in order to find out what it was all about?

Dr Keddie's article on the Montrose bicentenary and your news item on the Sunnyside Museum $(6,98-102 ; 104)$ made a happy conjunction, and as a former member of staff at Montrose (under John Colquhoun Anderson) these features of the Bulletin also induced a profound nostalgia and happiest memories of the College's Spring Quarterly Meeting of last year on the occasion of the Sunnyside bicentenary. The history of Sunnyside has already been very ably documented, but as with the Open University, no one hand could do justice to this astonishing institution. Present members of the staff at Montrose will I hope bear with me if I indulge my own memory to the extent of recalling that even in the days when there was only one consultant, no psychologists at all, no social worker and no pharmacist, the hospital provided a quality of care which I have never seen bettered, and rarely equalled: what is more, even during the short span of my own period at Sunnyside I was aware of four members of the junior medical staff who went on to become consultants in psychiatry, and one of them a professor-and this at a time when we had no registrars at all.

And this provides a neat transition passage to the last of the juicy morsels from your issue of June of this yearsurely a journalistic coup of rare quality: I mean of course the engaging account of 'Conversations with Sir Denis Hill' (6, 74-77; 94-97) which revealed so well the refreshing candour and originality of his approach. Speaking as a retired general psychiatrist brought up in the traditions of a generation ago and long removed from contacts with academic centres, I was fascinated by the forthright declaration of Sir Denis Hill on the antithesis between academic ability and therapeutic skill. Which provides for a quick ritornello to the subject of Sunnyside Royal, and a little coda in conclusion: among the last of my duties in Montrose was to help with the transcription of case notes from the old bound volume format into the modern loose-leaf version (I think it is not unfair to say that John Anderson, on the brink of retirement, was aware that the image of psychiatry was changing rapidly), and the perusal and sifting of the old bound volumes lent a heavy emphasis to the impression that at Sunnyside there had been for many generations a persisting tradition of humane care which would bear comparison with any in the world, quite detached from the formal paraphernalia of quasi-neuro-psychiatric minutiae of which Dr Launer writes so eloquently.

Finally, a note on the crisis of identity among psychiatrists which seems to surface from time to time in your columns; on this topic, I believe your news item on the opening of the Sunnyside museum reflects credit on the contributions which psychiatric hospitals have made to medical and nursing practice in hospitals throughout the Kingdom: how many hospitals of any kind are prepared to throw open their gates to the public as Sunnyside now does? But then, where did the practice of unrestricted visiting for patients begin, or for that matter the free availability of medical and nursing staff for consultation with relatives, or imaginative decor of wards and the use of wall paintings and informal furnishing to create a domestic atmosphere in what was once a meagre provision for paupers from public funds? I believe that in psychiatric traditions we have a great deal in which we can take some modest pride in having pioneered unostentatious reforms many of which are still percolating through to our more technologically-minded colleagues.

I have perhaps been at once too diffuse and too effusive, but I hope that at least you will be in no doubt that the College Bulletin continues to provide refreshment and stimulation for eager readers.

John COLLinson

\section{Cartwright Lane}

Beverley, Humberside

\section{Training in psychotherapy}

\section{DeAR SiR}

I found Professor Brandon's paper (Bulletin, July 1982, 6 , $120)$ really excellent in its consistent relevance, realism and economy.

My difference in view is about his apparent wish to perpetuate the split between general psychiatry and psychotherapy. Surely the training of general psychiatrists must include acquiring psychotherapeutic skills and insights-yet he writes as though these latter are forever to be found in taking yet further training, etc, extra to 'normal' training.

I would like to assert that there is now an eclectic body of knowledge called psychotherapy. It only obliges those of religious temperament to claim it belongs exclusively to ritualized, elitist, social groups. Thus we can reject much of Freud's meta-psychology. We would be foolish to reject his brilliant clinical insights and his descriptions of mental mechanisms, transference phenomena etc.

Also, there is the challenge of the body-mind problem. As we find more and more clever pills for patients it will be surely more and more exciting to see how they 'define' as it were, different aspects of mental functioning (leaving, I suspect, always something beyond a mere organic story).

\section{Medical Department}

ANDREW CROWCROFT

County Hall, London SEI

\section{Dear Sir}

I am writing to correct a misunderstanding in the report on the Southern Division trainees day (Bulletin, August 1982, 6, 146-47), and should be grateful for space to make my views properly represented. I was quoted as saying 'that Balint groups were an appropriate way of providing psychoanalytic training'. This of course is nonsense. 